\title{
QOS EVALUATION OF CLOUD SERVICE ARCHITECTURE BASED ON ANP
}

\author{
Mingzhe Wang \\ School of Automation \\ Huazhong University of Science and Technology \\ Wuhan 430074, P.R.China \\ E-mail: mingzhew@gmail.com \\ Yu Liu* \\ School of Automation \\ Huazhong University of Science and Technology \\ Wuhan 430074, P.R.China \\ E-mail: Liuyu_9628@163.com
}

\begin{abstract}
The architecture framework evolution and the patterns of enterprise service architecture are changing as the rise of cloud computing technology. Referencing service oriented architecture (SOA), a QoS measuring method for cloud service architecture using ANP is presented by research on enterprise cloud service architecture modeling and simulation: we built the measuring metrics for cloud service architecture based on the model of cloud service architecture; Firstly determines the influence among indicators and constructs the control hierarchy and network of ANP structure model by the correlation analysis of executable CPN model simulation, then set up the QoS-ANP measuring model; Secondly, obtains the attribute values of alternatives by the CPN + CloudSim hybrid simulation according to QoS-ANP measurement metrics. The supermatrix is used to calculate the relative superiority of each metric element, so that we can finish the comprehensive ranking for the QoS of cloud service architecture. Finally, the feasibility of the method, which measures the QoS of cloud service architecture, is validated in a use case.
\end{abstract}

Key words: cloud computing, service architecture, ANP, evaluation metrics, Colored Petri Nets

\section{Introduction}

Since Dr. Saaty proposes the analytic network process (ANP) on the base of AHP, he has expounded the theory and application of ANP in several papers. ANP and AHP both make paired comparisons among elements according to the criteria, and the relative importance of each element or alternative can be obtained.

(Gong, Liu, Sun, and Zhao, 2007) uses ANP to select the supplier that meet their own needs. (Chen, 2004) applies ANP to evaluate the performance for coordination of supply and demand. They take alternatives as a cluster, which constitutes the network together with indexes. The ranking of alternatives can be obtained directly from the result of interaction among elements. (Dong, and Xue, 2008) uses ANP to evaluate the performance of supply chain management. (Zhao, and Xin, 2004) assesses the scientific and technological strength in different regions by means of ANP. They make alternatives independent from

\footnotetext{
${ }^{*}$ Corresponding author

Project supported by the National Nature Science Foundation of China (No. 61273207 )
} 
the network, without considering feedback from alternatives to indexes.

We use the non-functional attributes of cloud computing application system to measure the cloud services architecture. (Kazman, Klein, Barbacci, Longstaff, Lipson, and Carriere, 1998) proposed an evaluation method for information systems architecture named ATAM (Architecture Tradeoff Analysis Method); (Huang, Luo, Qiu, Luo, and Tan, 2003) applies ATAM to evaluate the enterprise architecture and obtains an extensive application; (Huang, Luo, Qiu, Luo, and Tan, 2003) measures the QoS of Web service using ANP. In this paper, we developed a QoS measuring method for cloud service architecture using ANP based on research on enterprise cloud service architecture modeling and simulation. The detailed steps are as follows: (1) Build the control hierarchy and network of ANP structure model using the cloud architecture model simulation and coupling appraisal; (2) Analyze data obtained from qualitative judgment and hybrid simulation to get the influence between metric elements in the network of ANP; (3) Obtain the attribute values of alternatives set from the CPN + CloudSim hybrid simulation, according to QoS-ANP measurement metrics; (4) Use supermatrix to calculate the relative superiority of each metric element and identify the comprehensive ranking for the QoS of cloud service architecture.

\section{The Evaluation Steps of Cloud Service Architecture}

\subsection{The Modeling of Cloud Service Architecture}

For a typical three layered architecture of cloud computing (Luo, Jin, Song, and Dong, 2011), such as , SaaS (Software as a Service), PaaS (Platform as a Service), IaaS (Infrastructure as a Service), the purpose of the cloud service architecture is to provide dynamic computing service patterns that change with the need by sharing virtual resource pool. The Service-oriented Architecture (SOA), as a top-level architecture design principle and a management method for the enterprise information construction is focused and adopted by more and more researchers. This paper creates the enterprise cloud service architecture design model based on the Department of Defense Architecture Framework Version 2.0 (DoDAF V2.0), the Open Group Architecture Framework (TOGAF) and the Cloud Computing Modeling Notation (CCMN).

The users' requirements and the development and integration of system can be associated for achieving the interoperability of System of Systems (SoS) by cloud service architecture. For example, a service viewpoint model of parking management system is established using DODAF in Figure 1. The model depicts a solution based on the service and exhibits the services and service compositions that support the operational activities. The model also shows the exchange among service resource flow.

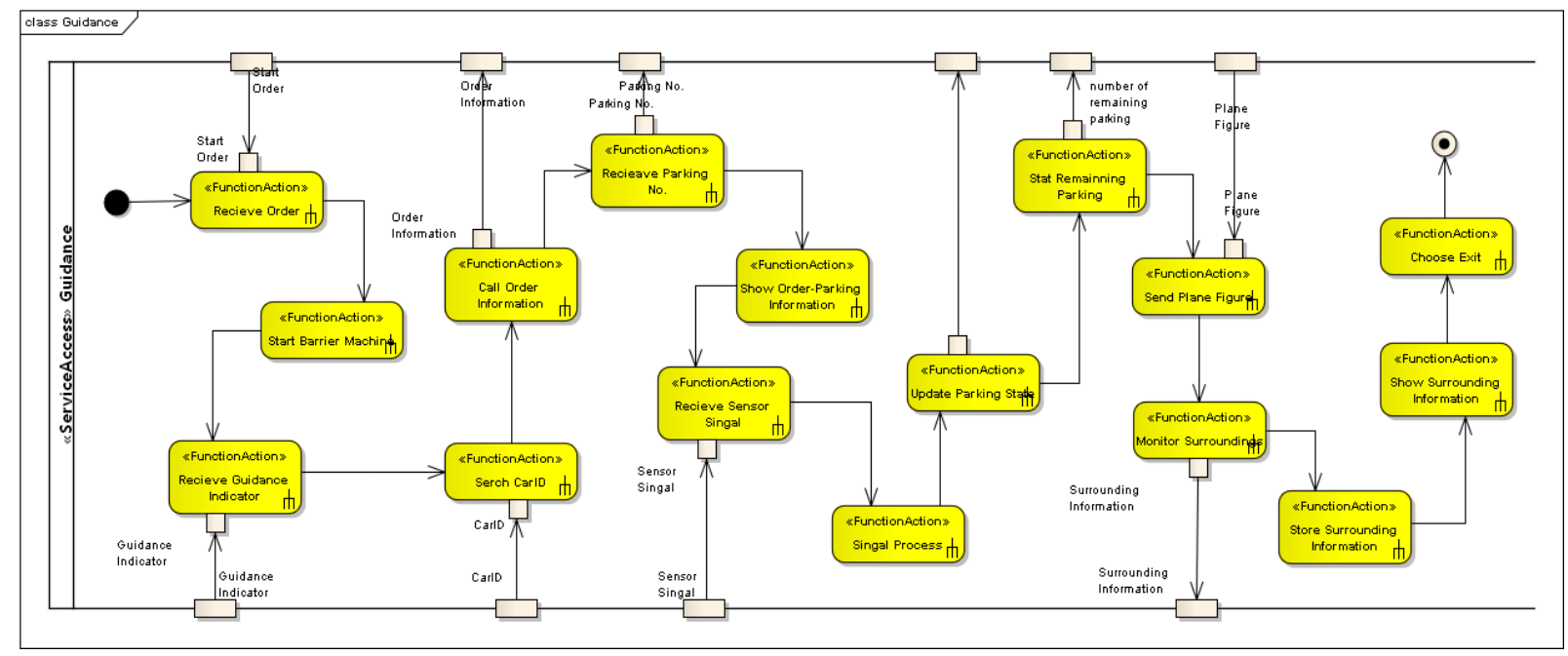


Figure 1 . The model of services functionality description for parking system

The system business scenarios and diversity of cloud service need can be revealed vividly and standardized by the viewpoint model. Since the viewpoint models are static, the simulation and the analysis of the model is not executable. Thus, the viewpoint models must be translated into executable model in order to acquiring the dynamic attribute value of Quality of Service (QoS) of the cloud service architecture and the performance.

\subsection{CPN +CloudSim hybrid simulation}

Colored Petri Net (CPN) is a high-level Petri net. CPN is a widely-used technique for the modeling of discrete event dynamic systems. CloudSim is a cloud computing simulator, which is developed by The University of Melbourne in Australia and can simulate the background process of the cloud computing application. A hybrid simulation platform is built in this paper, which combines the advantages of both the CPN and CloudSim.

The corresponding CPN model is created Based on the viewpoint model of system cloud service architecture. For instance, Figure 2 shows the top-level CPN model of management support and information system. The simulation of operational event flow is executed by the "substitution transitions" and "fusion places" of CPN; the host server, data center, agent, virtual machine, and infrastructure (network, cloud coordinator) are simulated by CloudSim; the interaction between operational event and server is identified by the Service Viewpoint model SvcV-1 and SvcV-2, and the simulation result of CloudSim will be returned to CPN model. Therefore, the CPN +CloudSim hybrid simulation platform is established and non-functional attributes of system cloud service architecture can be obtained by simulation.

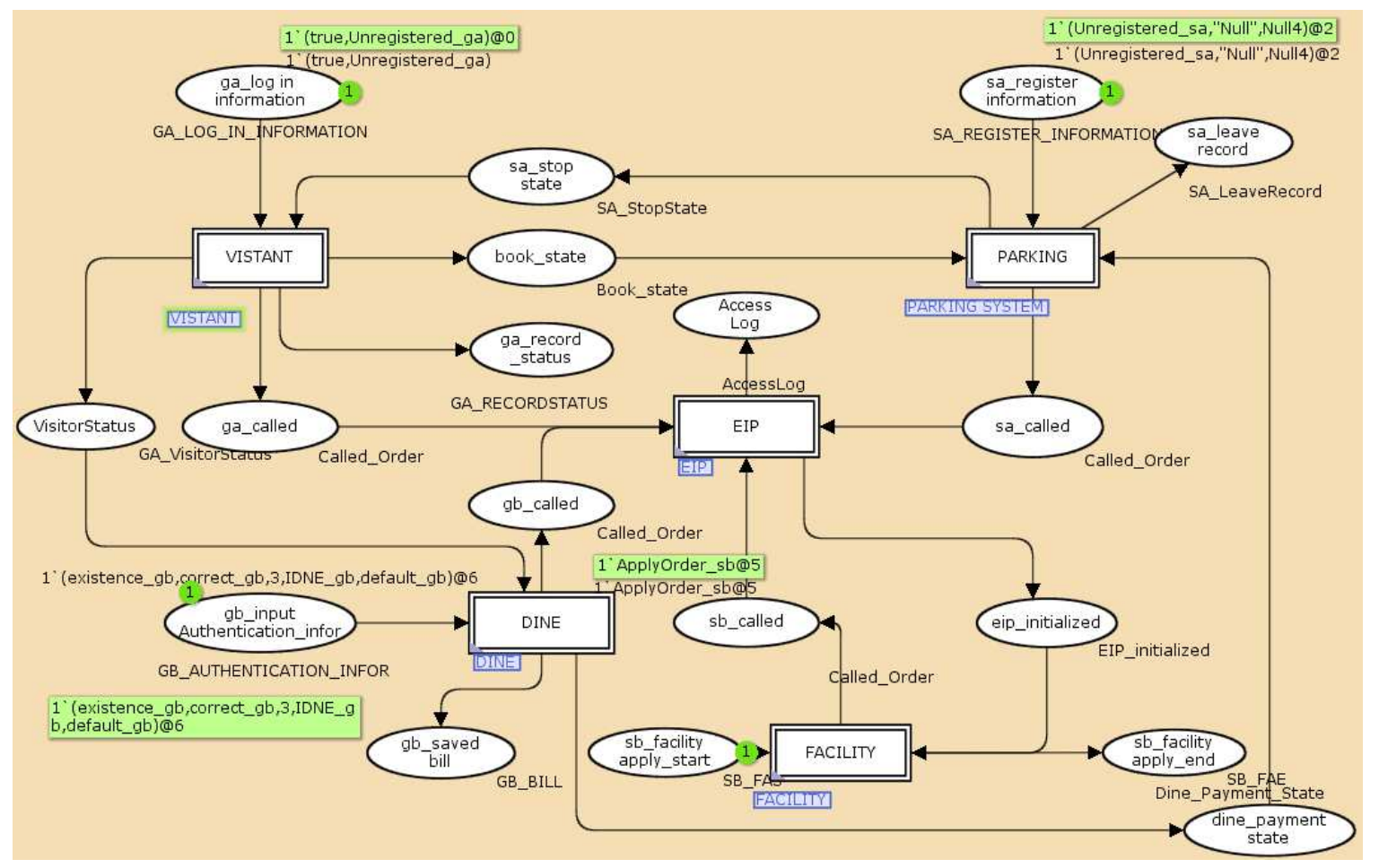

Figure 2. The top-level CPN model of management support and information system 


\subsection{The Evaluation of Cloud Service Architecture}

Different systems have different cloud service requirements and the service viewpoint model and CPN model will be different based on the cloud service architecture. Therefore, the value of non-functional attributes of cloud service architecture will be different based on the hybrid simulation of CPN and CloudSim, that is, the QoS of cloud service architecture will be variance. An evaluation method for the QoS of cloud service architecture is required to measuring the architecture in cloud context.

This paper uses ANP method to evaluating the QoS of cloud service architecture. The ANP helps to choose the optimal architecture if it can be seen as a filter mode. In other words, the ranking of the architecture obtained by ANP is equivalent to utilizing the filter model to find the architectures with different quality level.

The QoS of cloud service architecture mainly is a non-functional attribute. Therefore, the alternatives in ANP network have no feedback impact on the metrics. The alternatives set can be separated from network, and just consider the interrelationship among metric elements. And the influence among metric elements can be measured by using the correlation of metrics. The weight of each metric element is obtained from supermatrix. Finally, linear weighted method is applied to compare the alternatives.

\section{The ANP Evaluation of Cloud Service Architecture}

According to the general analysis steps of ANP, our first enhancement is to construct the control hierarchy and network of ANP model. The indicator in metrics is the same as the element in the network of ANP. The judgment matrix can be obtained by pairwise comparisons of element in the network under specific criteria. However, the importance between elements is got through the qualitative judgment of expert. This paper combines qualitative judgment with quantitative simulation statistics, analyzes the correlation between indicators, and measures the influence of indicator using correlation, so that we can construct judgment matrix well-founded.

\subsection{The QoS Measuring Metrics of Cloud Service Architecture}

We built a set of three-layer metrics by combining cloud computing three layers architecture (Yong, Wei, and Jie, 2012), and the metric elements can be divided into benefits and costs, as shown in Figure 3.

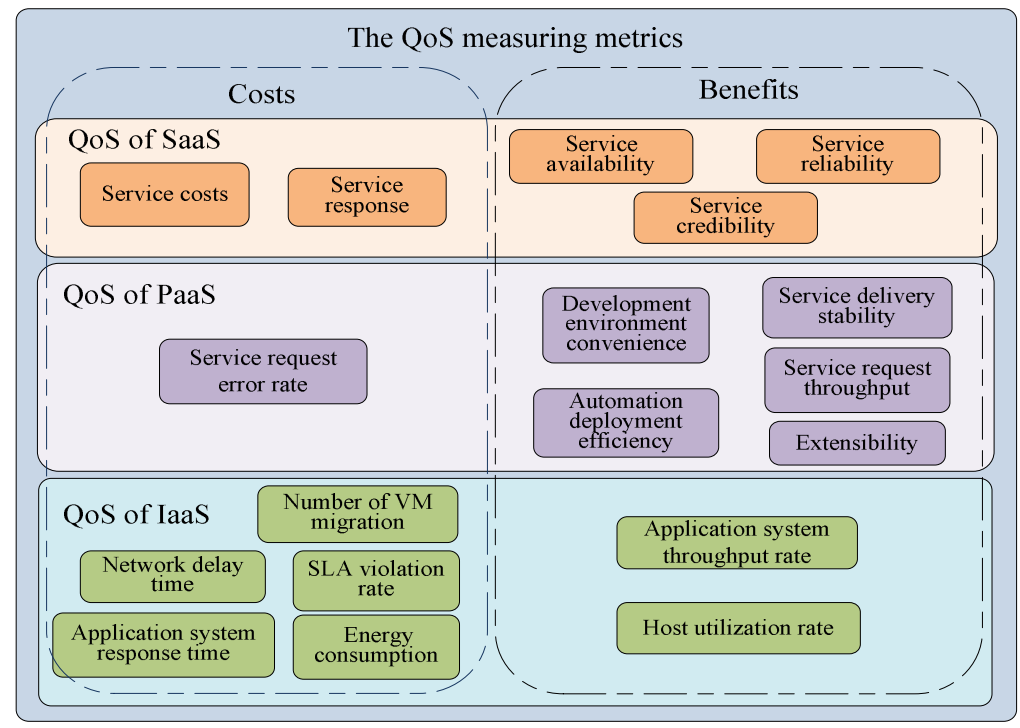


Figure 3. The QoS measuring metrics of cloud service architecture

The detailed descriptions on metric elements are shown in Table 1. Among them, the values of performance indicators are obtained by the CPN +CloudSim hybrid simulation, and the values of qualitative indicators also are obtained by adopting five measuring method..

Table 1. The detailed description of QoS metric elements

\begin{tabular}{|c|c|c|}
\hline Cluster & Metric elements & Description \\
\hline \multirow{7}{*}{$\begin{array}{c}\mathrm{C}_{1} \text { The } \\
\text { QoS of IaaS }\end{array}$} & $\mathrm{C}_{11}$ Network delay time & $\begin{array}{l}\text { the time taking for a service to travel across the } \\
\text { network }\end{array}$ \\
\hline & $\begin{array}{l}\mathrm{C}_{12} \text { Application system } \\
\text { response time }\end{array}$ & $\begin{array}{l}\text { the average time elapsed between the time when user } \\
\text { makes a request and the time when user receives the } \\
\text { response result }\end{array}$ \\
\hline & $\begin{array}{l}\mathrm{C}_{13} \text { Application system } \\
\text { throughput rate }\end{array}$ & $\begin{array}{l}\text { the average rate of successful data delivery over a } \\
\text { communication channel }\end{array}$ \\
\hline & $\mathrm{C}_{14}$ Energy consumption & the energy consumption for completing cloud task \\
\hline & $\mathrm{C}_{15}$ SLA violation rate & the rate of service level agreement violations \\
\hline & $\mathrm{C}_{16}$ Host utilization rate & the utilization rate of cloud infrastructure resource \\
\hline & $\mathrm{C}_{17}$ Number of VM migration & $\begin{array}{l}\text { the number of virtual machine migration in the } \\
\text { process of the cloud task execution process }\end{array}$ \\
\hline \multirow{6}{*}{$\begin{array}{l}\mathrm{C}_{2} \text { The } \\
\text { QoS Of Paas }\end{array}$} & $\mathrm{C}_{21}$ Extensibility & the ability to expand the business scale of cloud task \\
\hline & $\mathrm{C}_{22}$ Service request error rate & $\begin{array}{l}\text { the average occurring rate of unexpected handling } \\
\text { in per unit time }\end{array}$ \\
\hline & $\mathrm{C}_{23}$ Service request throughput & the processed service number in per unit time \\
\hline & $\mathrm{C}_{24}$ Service delivery stability & $\begin{array}{l}\text { the changeability of processing time when the service } \\
\text { is normally used and efficient. }\end{array}$ \\
\hline & $\begin{array}{l}\mathrm{C}_{25} \text { Development environment } \\
\text { convenience }\end{array}$ & $\begin{array}{l}\text { the level of reduced time for application system } \\
\text { development }\end{array}$ \\
\hline & $\begin{array}{l}\mathrm{C}_{26} \text { Automation deployment } \\
\text { efficiency }\end{array}$ & $\begin{array}{l}\text { the level of reduced time for application system } \\
\text { automatic deployment }\end{array}$ \\
\hline \multirow{5}{*}{$\begin{array}{c}\mathrm{C}_{3} \text { The } \\
\text { QoS of SaaS }\end{array}$} & $\mathrm{C}_{31}$ Service response time & $\begin{array}{l}\text { the time elapsed between the time when user makes a } \\
\text { request and the time when user receives the response } \\
\text { result. }\end{array}$ \\
\hline & $\mathrm{C}_{32}$ Service costs & the cost for using the service once \\
\hline & $\mathrm{C}_{33}$ Service availability & $\begin{array}{l}\text { the ratio of the number of successful service to the } \\
\text { total number }\end{array}$ \\
\hline & $\mathrm{C}_{34}$ Service reliability & $\begin{array}{l}\text { the ratio of successful execution times to the execution } \\
\text { times }\end{array}$ \\
\hline & $\mathrm{C}_{35}$ Service credibility & $\begin{array}{l}\text { the multiply of the credibility of service itself and the } \\
\text { credibility of PaaS }\end{array}$ \\
\hline
\end{tabular}

In this Table, the metric elements in three clusters are not independent from each other. For example, the metric element $C_{11}$ (network traffic delay time) depends on the metric element $C_{12}$ (application system response time) in the same cluster $\mathrm{C}_{1} ; \mathrm{C}_{17}$ (number of VM migration), $\mathrm{C}_{14}$ (energy consumption) and $\mathrm{C}_{16}$ (host utilization rate) are interrelated; the cluster $\mathrm{C}_{2}$ and $\mathrm{C}_{3}$ are the same. In addition, the metric elements in different cluster also influence each other. For instance, there are dependencies between $\mathrm{C}_{31}$ (service response time) and $\mathrm{C}_{12}$ (application system response time).

\subsection{Measuring Influence With Correlation}

The influence between metric elements is measured by the correlation between them. We assume the influence is proportional to the degree of correlation of metric elements, and we establish the following 
relationship:

$$
F_{X Y}=A\left|\rho_{X Y}\right|+B
$$

Where $F_{X Y}$ is the influence between $X$ and $Y$, the $A$ and $B$ is constant. In that way, the correlation coefficient between $\mathrm{X}$ and $\mathrm{Y}$ indicates the influence of them.

Simulation data is collected in the CPN +CloudSim hybrid simulation. Using the simulation data and the formula shown above, we can calculate influence for any two indicators. Figure 4 depicts the correlation degree between four pairs of indicators. In this figure, the strongest influence relationship between energy consumption and application system response time is obvious, and the network delay time have weak influence on host utilization rate.
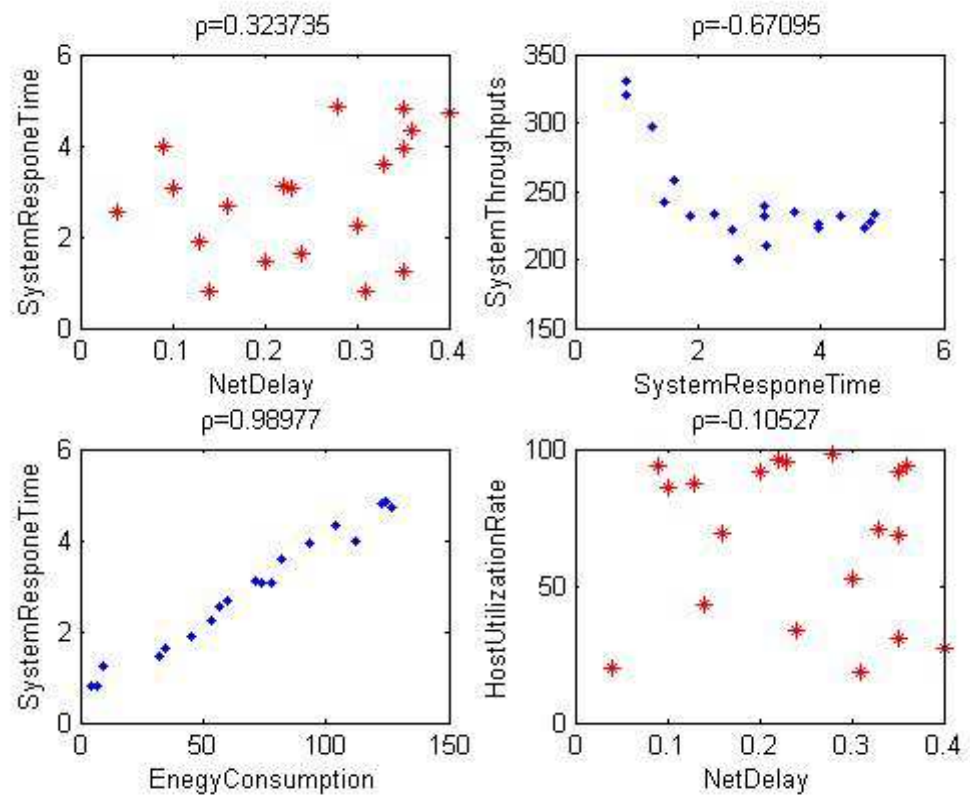

Figure 4. The four pairs of indicators scatter plot

We use the QoS indicator of IaaS as an example and obtain the correlation coefficient of indicators by using correlation analysis, as shown in Table 2.

Table 2. The correlation coefficient of indicators

\begin{tabular}{cccccccc}
\hline Index & $\mathrm{C}_{11}$ & $\mathrm{C}_{12}$ & $\mathrm{C}_{13}$ & $\mathrm{C}_{14}$ & $\mathrm{C}_{15}$ & $\mathrm{C}_{16}$ & $\mathrm{C}_{17}$ \\
\hline $\mathrm{C}_{11}$ & 1 & -0.86467 & -0.92705 & -0.89425 & -0.87097 & -0.82988 & -0.86708 \\
$\mathrm{C}_{12}$ & -0.86467 & 1 & 0.977148 & 0.98844 & 0.771209 & 0.814284 & 0.993562 \\
$\mathrm{C}_{13}$ & -0.92705 & 0.977148 & 1 & 0.983403 & 0.37477 & 0.884821 & 0.985204 \\
$\mathrm{C}_{14}$ & -0.89425 & 0.98844 & 0.983403 & 1 & 0.504356 & 0.868234 & 0.998448 \\
$\mathrm{C}_{15}$ & -0.87097 & 0.771209 & 0.37477 & 0.504356 & 1 & 0.249676 & 0.273458 \\
$\mathrm{C}_{16}$ & -0.82988 & 0.814284 & 0.884821 & 0.868234 & 0.249676 & 1 & 0.889513 \\
$\mathrm{C}_{17}$ & -0.86708 & 0.993562 & 0.998448 & 0.998448 & 0.273458 & 0.889513 & 1 \\
\hline
\end{tabular}

When the influence network of indicators is determined, we can construct the judgment matrix using the 
correlation coefficient of indicators. For example, by comparing the importance from the indicator B, C, $\mathrm{D}$ to the indicator $\mathrm{A}$, the correlation analysis matrix can be built as follow:

\begin{tabular}{c|ccc}
$\mathrm{A}$ & $\mathrm{B}$ & $\mathrm{C}$ & $\mathrm{D}$ \\
\hline $\mathrm{B}$ & 1 & $\left|\rho_{A B} / \rho_{A C}\right|$ & $\left|\rho_{A B} / \rho_{A D}\right|$ \\
$\mathrm{C}$ & & 1 & $\left|\rho_{A C} / \rho_{A D}\right|$ \\
$\mathrm{D}$ & & & 1
\end{tabular}

If $\left|\rho_{A B} / \rho_{A C}\right|>1$, then the influence from B to A is greater than the influence from $\mathrm{C}$ to $\mathrm{A}$, and the element of matrix should bigger than 1 .

If $\left|\rho_{A B} / \rho_{A C}\right|<1$, then the influence from $\mathrm{C}$ to $\mathrm{A}$ is greater than the influence from $\mathrm{B}$ to $\mathrm{A}$, and the element of matrix should smaller than 1.

According to the correlation coefficient ratio, we can qualitatively compare the influence between metric elements. Similarly, we can get other element values in the judgment matrix, and obtain the limit supermatrix by setting up the unweighted supermatrix and weighted supermatrix. The limit supermatrix is used to calculate the relative superiority of each metric element, which helps to finish the comprehensive ranking for the QoS of cloud service architecture.

\section{Case Study}

Treating a management support and information system cloud computing application research as the background, we selected five systems as objects of the evaluation. These five systems are the visitor management system, the catering management system, the enterprise information portal, the parking management system and the facility management system. By analyzing the five systems, QoS-ANP network structural models of cloud service architecture are constructed as shown in Figure 5. The goal of control hierarchy in the model is the QoS of cloud service architecture, and is treated as the main criterion to compare between all elements.

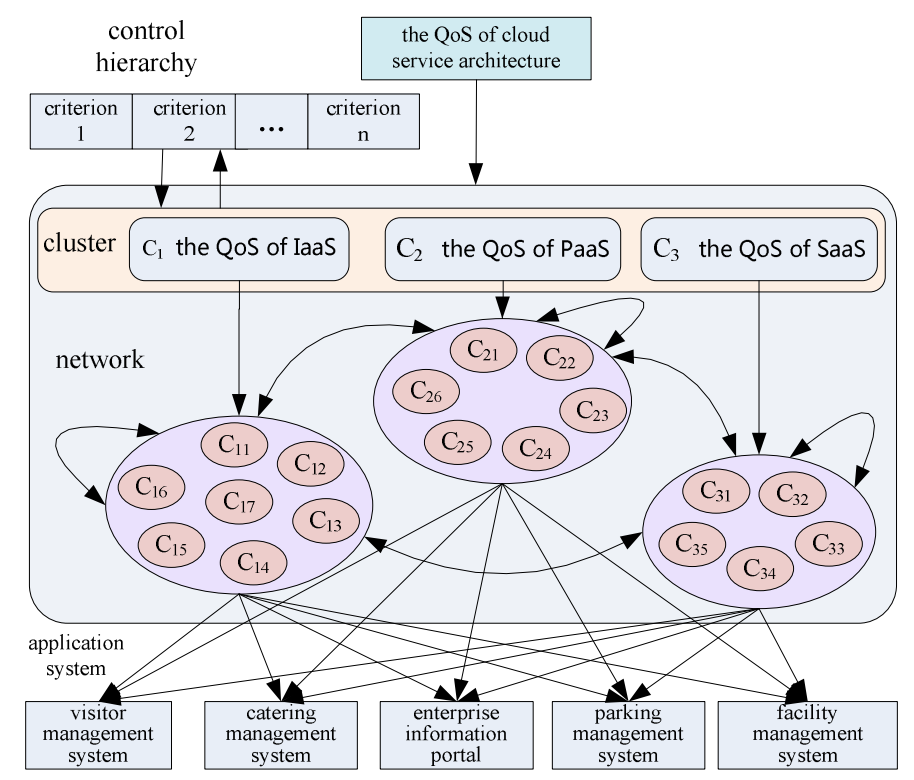


Figure 5. The QoS-ANP network model of cloud service architecture

We applied SD (SuperDecisions) software to build the ANP network structure model of the cloud service architecture mentioned above. Firstly, we make qualitative judgment on the influences between metric elements based on the definitions of metric elements and models. Then we compare the importance between metric elements under the corresponding criterion, based on the correlation analysis of metric elements. Take $\mathrm{C}_{11}$ (network delay) for instance, and the correlation analysis matrix is showed bellow.

\begin{tabular}{c|ccc}
$\mathrm{C}_{11}$ & $\mathrm{C}_{12}$ & $\mathrm{C}_{13}$ & $\mathrm{C}_{17}$ \\
\hline $\mathrm{C}_{12}$ & 1 & $\left|\rho_{C_{11} C_{12}} / \rho_{C_{11} C_{13}}\right|=0.933$ & $\left|\rho_{C_{11} C_{12}} / \rho_{C_{11} C_{17}}\right|=0.997$ \\
$\mathrm{C}_{13}$ & & 1 & $\left|\rho_{C_{11} C_{13}} / \rho_{C_{11} C_{17}}\right|=1.069$ \\
$\mathrm{C}_{17}$ & & & 1
\end{tabular}

Using the correlation analysis matrix to construct judgment matrix as follow:

\begin{tabular}{c|ccc|c}
$\mathrm{C}_{11}$ & $\mathrm{C}_{12}$ & $\mathrm{C}_{13}$ & $\mathrm{C}_{17}$ & Eigenvector \\
\hline $\mathrm{C}_{12}$ & 1 & $1 / 4$ & $1 / 3$ & 0.117211 \\
$\mathrm{C}_{13}$ & & 1 & 3 & 0.614411 \\
$\mathrm{C}_{17}$ & & & 1 & 0.268368
\end{tabular}

Similarly, we calculate the eigenvector of the judgment matrix to get the unweighted supermatrix using correlation analysis between metric elements. And we multiply the unweighted supermatrix by the weight matrix to get the stable limit supermatrix, as shown in Table 3 .

Table 3. The limit supermatrix

\begin{tabular}{|l|c|c|c|c|c|c|c|c|}
\hline & $\mathbf{C}_{\mathbf{1 1}}$ & $\mathbf{C}_{\mathbf{1 2}}$ & $\mathbf{C}_{\mathbf{1 3}}$ & $\ldots$ & $\mathbf{C}_{\mathbf{3 2}}$ & $\mathbf{C}_{\mathbf{3 3}}$ & $\mathbf{C}_{\mathbf{3 4}}$ & $\mathbf{C}_{\mathbf{3 5}}$ \\
\hline $\mathbf{C}_{\mathbf{1 1}}$ & 0.083668 & 0.083668 & 0.083668 & $\ldots$ & 0.083668 & 0.083668 & 0.083668 & 0.083668 \\
\hline $\mathbf{C}_{\mathbf{1 2}}$ & 0.017629 & 0.017629 & 0.017629 & $\ldots$ & 0.017629 & 0.017629 & 0.017629 & 0.017629 \\
\hline $\mathbf{C}_{\mathbf{1 3}}$ & 0.082106 & 0.082106 & 0.082106 & $\ldots$ & 0.082106 & 0.082106 & 0.082106 & 0.082106 \\
\hline $\mathbf{C}_{\mathbf{1 4}}$ & 0.035096 & 0.035096 & 0.035096 & $\ldots$ & 0.035096 & 0.035096 & 0.035096 & 0.035096 \\
\hline $\mathbf{C}_{\mathbf{1 5}}$ & 0.095168 & 0.095168 & 0.095168 & $\ldots$ & 0.095168 & 0.095168 & 0.095168 & 0.095168 \\
\hline $\mathbf{C}_{\mathbf{1 6}}$ & 0.020918 & 0.020918 & 0.020918 & $\ldots$ & 0.020918 & 0.020918 & 0.020918 & 0.020918 \\
\hline $\mathbf{C}_{\mathbf{1 7}}$ & 0.059497 & 0.059497 & 0.059497 & $\ldots$ & 0.059497 & 0.059497 & 0.059497 & 0.059497 \\
\hline $\mathbf{C}_{\mathbf{2 1}}$ & 0.054671 & 0.054671 & 0.054671 & $\ldots$ & 0.054671 & 0.054671 & 0.054671 & 0.054671 \\
\hline $\mathbf{C}_{\mathbf{2 2}}$ & 0.016932 & 0.016932 & 0.016932 & $\ldots$ & 0.016932 & 0.016932 & 0.016932 & 0.016932 \\
\hline $\mathbf{C}_{\mathbf{2 3}}$ & 0.079275 & 0.079275 & 0.079275 & $\ldots$ & 0.079275 & 0.079275 & 0.079275 & 0.079275 \\
\hline $\mathbf{C}_{\mathbf{2 4}}$ & 0.013113 & 0.013113 & 0.013113 & $\ldots$ & 0.013113 & 0.013113 & 0.013113 & 0.013113 \\
\hline $\mathbf{C}_{\mathbf{2 5}}$ & 0.106314 & 0.106314 & 0.106314 & $\ldots$ & 0.106314 & 0.106314 & 0.106314 & 0.106314 \\
\hline $\mathbf{C}_{\mathbf{2 6}}$ & 0.020415 & 0.020415 & 0.020415 & $\ldots$ & 0.020415 & 0.020415 & 0.020415 & 0.020415 \\
\hline $\mathbf{C}_{\mathbf{3 1}}$ & 0.079221 & 0.079221 & 0.079221 & $\ldots$ & 0.079221 & 0.079221 & 0.079221 & 0.079221 \\
\hline $\mathbf{C}_{\mathbf{3 2}}$ & 0.074212 & 0.074212 & 0.074212 & $\ldots$ & 0.074212 & 0.074212 & 0.074212 & 0.074212 \\
\hline $\mathbf{C}_{\mathbf{3 3}}$ & 0.096434 & 0.096434 & 0.096434 & $\ldots$ & 0.096434 & 0.096434 & 0.096434 & 0.096434 \\
\hline $\mathbf{C}_{\mathbf{3 4}}$ & 0.042439 & 0.042439 & 0.042439 & $\ldots$ & 0.042439 & 0.042439 & 0.042439 & 0.042439 \\
\hline $\mathbf{C}_{\mathbf{3 5}}$ & 0.022891 & 0.022891 & 0.022891 & $\ldots$ & 0.022891 & 0.022891 & 0.022891 & 0.022891 \\
\hline
\end{tabular}

By applying $\mathrm{CPN}+\mathrm{Cloudsim}$ to interactively simulate the executable CPN models of the five application 
systems, we calculate the QoS indicator values of cloud service architecture of each application system. After the indicator values are nondimensionalizaed, the treated QoS indicator values are obtained.

Table 4. The treated QoS indicator values

\begin{tabular}{|c|c|c|c|c|c|}
\hline System & $\begin{array}{c}\text { visitor } \\
\text { management } \\
\text { system }\end{array}$ & $\begin{array}{c}\text { catering } \\
\text { management } \\
\text { system }\end{array}$ & $\begin{array}{c}\text { enterprise } \\
\text { information } \\
\text { portal }\end{array}$ & $\begin{array}{c}\text { parking } \\
\text { management } \\
\text { system }\end{array}$ & $\begin{array}{c}\text { facility } \\
\text { management } \\
\text { system }\end{array}$ \\
\hline $\mathrm{C}_{11}$ & 0.128573 & 0.08479 & 0.405114 & 0.186107 & 0.195417 \\
\hline $\mathrm{C}_{12}$ & 0.13578 & 0.092199 & 0.380666 & 0.169792 & 0.221563 \\
\hline $\mathrm{C}_{13}$ & 0.180701 & 0.178397 & 0.191426 & 0.18175 & 0.267727 \\
\hline $\mathrm{C}_{14}$ & 0.126929 & 0.09577 & 0.319397 & 0.135478 & 0.322426 \\
\hline $\mathrm{C}_{15}$ & 0.199773 & 0.199773 & 0.210513 & 0.21514 & 0.174801 \\
\hline $\mathrm{C}_{16}$ & 0.225563 & 0.169463 & 0.20236 & 0.223203 & 0.179412 \\
\hline $\mathrm{C}_{17}$ & 0.138704 & 0.096617 & 0.391201 & 0.175861 & 0.197617 \\
\hline $\mathrm{C}_{21}$ & 0.199397 & 0.195687 & 0.2147 & 0.23093 & 0.159286 \\
\hline $\mathrm{C}_{22}$ & 0.195974 & 0.194753 & 0.217069 & 0.214095 & 0.178108 \\
\hline $\mathrm{C}_{23}$ & 0.183023 & 0.176685 & 0.205239 & 0.197602 & 0.237451 \\
\hline $\mathrm{C}_{24}$ & 0.200212 & 0.200294 & 0.20009 & 0.200416 & 0.198989 \\
\hline $\mathrm{C}_{25}$ & 0.1 & 0.2 & 0.3 & 0.2 & 0.2 \\
\hline $\mathrm{C}_{26}$ & 0.2 & 0.25 & 0.25 & 0.15 & 0.15 \\
\hline $\mathrm{C}_{31}$ & 0.194084 & 0.188189 & 0.176247 & 0.185374 & 0.256105 \\
\hline $\mathrm{C}_{32}$ & 0.138501 & 0.096271 & 0.404955 & 0.172123 & 0.18815 \\
\hline $\mathrm{C}_{33}$ & 0.198251 & 0.198251 & 0.206997 & 0.206997 & 0.189504 \\
\hline $\mathrm{C}_{34}$ & 0.200924 & 0.200924 & 0.189376 & 0.187067 & 0.221709 \\
\hline $\mathrm{C}_{35}$ & 0.2 & 0.2 & 0.2 & 0.2 & 0.2 \\
\hline $\mathrm{Score}_{2}$ & 0.179232 & 0.16741 & 0.257625 & 0.195354 & 0.200377 \\
\hline $\mathrm{Rank}$ & 4 & 5 & 1 & 3 & 2 \\
\hline & & & & & \\
\hline
\end{tabular}

The comprehensive measuring ranking of QoS-ANP cloud service architecture is: the enterprise information portal $>$ the facility management system $>$ the visitor management system $>$ the parking management system > the catering management system. The cloud service architecture of the enterprise information portal is the optimal.

\section{Conclusion}

This paper develops QoS-ANP measuring method for cloud service architecture using ANP based on enterprise cloud service architecture modeling and simulation. We construct the measuring metrics using CPN simulation and analysis. The influence among metric elements is measured by using the correlation of metrics. The supermatrix is used to calculate the relative superiority of each metric element, so that we can apply the linear weighted method to finish the comprehensive rank for the QoS of cloud service architecture.

The measuring method of QoS-ANP can be easily extended to rank infinite alternatives based on QoS optimization. The idea of QoS-ANP can also be applied to analyze the trade-off decision with multi-attribute or multi-objective. 


\section{References}

Chen, Z.X. (2004). Model and Algorithms of Supply and Demand Coordination Performance Measurement Based on ANP Theory. Computer Integrated Manufacturing Systems (03), 286-291.

Dong, Y.L., \& Xue, L. (2008). Evaluation Model and Algorithm of Green Supply Chains' Management Performance Based on ANP Theory. Soft science (11), 56-63.

Gong, J.T., Liu, B., Sun, L.Y., \& Zhao, P. (2007). Analytic Network Process and Applica tion for Supplier Selection. Industrial Engineering Journal (02), 77-80.

Huang, L., Luo, A.M., Qiu, D.S., Luo, X.S., \& Tan, Y.J. (2003).ATAM: A Method for the Evaluation of C4ISR Architecture. Fire Control \& Command Control (02), 19-22.

Kazman,R., Klein, M., Barbacci,M., Longstaff,T., Lipson,H. \& Carriere,J.(1998). The architecture tradeoff analysis method. Fourth IEEE International Conference, 78, 10-14.

Karim, R., Chen D., \& Chi-hung, C. (2011). An Enhanced PROMETHEE Model for QoS-Based Web Service Selection. 2011 IEEE International Conference on Services Computing (SCC2011) 81,536-543.

Luo, J.Z., Jin, J.H., Song, A.B., \& Dong, F. (2011). Cloud computing: architecture and key technologies. Journal on Communications(07), 3-21.

Saaty, T.L. (2004). Decision making - the Analytic Hierarchy and Network Processes (AHP/ANP). Journal of Systems Science and Systems Engineering, 13(1), 1-35.

Saaty, T.L., (1996). Decision Making with Dependence and Feedback. Pittsburgh, PA: RWS Publications.

Yong, G., Wei, Z., \& Jie, T. (2012). A Study of SLA Violation Compensation Mechanismin Complex Cloud Computing Environment. the Instrumentation, Measurement, Computer, Communication and Control (IMCCC 2012).

Zhao, G.J., \& Xin, X.Q. (2004). The Theoretical Analysis and Practical Application on ANP Method in Regional Scientific Strength Evaluation. Systems Engineering-Theory and Practice (05), 41-45. 